\title{
Decomposition of embodied exergy flows in manufactured products and implications for carbon tariff policies
}

\author{
Mei Liao • Chao Ma • Dongpu Yao • Huizheng Liu
}

Received: 15 July 2013 / Accepted: 15 July 2013 /

Published online: 24 August 2013

(C) The Author(s) 2013. This article is published with open access at Springerlink.com

\begin{abstract}
This article uses the concept of embodied exergy as metrics in designing incentive policy instruments to tackle the inefficiency of energy operations. Based on the second law of thermodynamics and energy's economic properties as both a private commodity and a public good, it maintains that energy can be measured by separating the useful exergy embodied in a manufactured product from its waste exergy (anergy) as emissions and sunk wastes in a production process. It is rational to benchmark the content of useful exergy embodied in products for any incentive policy design to encourage green production. This article uses trade data between China, Japan and the EU countries to compare the embodied exergy and waste exergy embodied in traded manufactured products. It proposes using a negative value-added tax as an incentive instrument instead of full-scale carbon tariffs to encourage green production and to fence against carbon evasion behaviour.
\end{abstract}

\section{Introduction}

If we look at global fuel energy resources from the perspective of environmental sustainability and greenhouse gas (GHG) mitigation, they should be treated as the common property of the global community. Despite the growing importance of international production networks in the world economy and a growing body of literature on embodied energy in trade, there is still limited literature on the effects of fragmentation of production and shifting trade patterns in energy consumption and GHG emissions. In contrast to the cross-boundary drive of industrial networking for fuel energy sourcing and consumption, the international community is still carrying out its GHG mitigation efforts in terms of segmented national commitments and policies. The international community is also troubled with so-called carbon leakages across the global production chains. Much environmental damage is due to the

M. Liao $(\square) \cdot$ C. Ma $\cdot$ D. Yao $\cdot$ H. Liu

Economics and Management School, Beijing University of Technology, 100 PingleyuanChaoyang

DistrictBeijing 100124, China

e-mail: liaomei@bjut.edu.cn 
increased scale of global economic activity and the divide between industrial countries and emerging economies.

Based on a rationale that the user pays, this article adopts a technical decomposition approach to measure the liability of GHG mitigation. By differentiating the useful energy (exergy) from waste energy (anergy) in the production process and tracking the emission routes of products flows across countries, it is found that the polluter-pay principle could be challenged in the context of global production chains and new trade patterns. The benefits of old classic polluter concept has been sliced and shifted to separate product importers.

The main forms of energy used in industry are biomass-based fuels, fossil fuels (coal, oil and natural gas) and renewable sources (sun, wind and water). For economic analysis, the conventional way of tabulating the energy consumption is based on the ratio of value of output to the quantity or cost of energy inputs, i.e., energy efficiency. One of the loopholes in this accounting method, however, is that the cost of energy inputs counted may induce a plausible conclusion that the manufacturer is the polluter who should take liability for the unavoidable cost of GHG emissions. Therefore, the polluter-pay principle targeting suppliers applies and underpins policies such as an ecotax or carbon tax. Further, with the growth of the global production value-chain, the producers, especially the multinational companies, will re-locate the polluting sectors outside their home countries to circumvent the tax burden. Intentional carbon tax evasion, instead of casual leakage, will surely become unavoidable.

\section{Embodied exergy analysis}

The interest in studying embodied exergy flow was triggered and developed roughly simultaneously in engineering (Georgescu-Roegen 1971) and environmental and biological circles (Odum 1996). Later, it appeared in the study on economics and international trade research (Costanza 1980; Moran et al. 2009). Different from the concept of embodied energy which is defined as the cumulative amount of commercial energy (fossil, renewable, nuclear) invested to extract, process and manufacture a product and transport it to its point of use, embodied exergy is defined as the amount of work the system can perform when it is brought into thermodynamic equilibrium ${ }^{1}$ with the environment (Jørgensen et al. 2004). Different from gross energy consumption data used in macroeconomic accounting and projections, embodied exergy is a product-specific accounting methodology which aims to capture the consumption mode of energy embodied in an entire product lifecycle. The purpose of analysing embodied exergy flow in manufactured products is to find how much useful energy is left and embodied in a product, and what quantities of emissions and waste caused by energy depreciation at different points of the production and consumption process should be assigned either to producers or to consumers for the mitigation duty.

The analysis here strives to defend three arguments:

1. The border-confined institutional mechanism, such as the carbon tariff scheme, based on the energy feedstock of individual countries' industries may cause

\footnotetext{
${ }^{1}$ This can be understood as a state in which an input of energy has been combusted to the full under set temperature and technical conditions.
} 
"carbon evasion" behaviour, that is, producers or even governmental decisionmakers may choose to segregate the production value-chain across borders and relocate energy-intensive and heavy polluted production processes in other countries to circumvent the environmental and financial liabilities imposed by the international GHG mitigation commitments.

2. Energy as traded goods should be treated as a commodity of dual property as possessing both features of non-exclusive public goods and tradable private goods. As feedstock input, its degradation property caused by its physical and dynamic effects can convert only a portion of energy into useful work (or exergy) and a certain amount of deadweight loss of energy caused by entropy effects and technological inefficiency (or anergy) will either turn into waste or GHG. Therefore, the focus of the emission problem should be directed at how to maximise exergy efficiency. It is misleading if we simply use total energy inputs as a base for calibrating carbon tariff rate.

3. In the context of the global production value-chain and cross-border products flow, the incentives for joint GHG mitigation efforts are not triggered by a levying tax on energy use. Rather, they are triggered by encouraging exergy efficiency.

This study has two purposes. Firstly, it explores the status quo of embodied exergy consumption flow in traded products between the EU and its major East Asian partners. Secondly, it discusses the distributional impact of embodied exergy consumption, the burden on both producers and consumers in different regions and countries and the potential positive and negative effects as a result of carbon mitigation policies.

This article begins with a critical review of embodied exergy approaches and their applications. The following sections include: the accounting methodology for embodied exergy flow (which is proposed and explained), an empirical study of the embodied exergy in traded manufactured products flow between the EU, China and Japan, an analysis of the findings and a discussion of the implications for carbonrelated trade policies.

\section{A critical review of embodied exergy approaches}

The concept of positive and negative values of embodied exergy

The exergy-based methods are grounded in the second law of thermodynamics which takes into account the unavoidable losses caused by the entropy effect. ${ }^{2}$ When using energy, we utilise the energy conversions along its way towards heat at environmental temperature. During this process not all the energy can be converted into work - only a certain available part of the energy, or a similar amount of mechanical work that could be extracted from it. This useful component of energy is called exergy. It is destroyed by every process or action, while the

\footnotetext{
${ }^{2}$ The traditional qualitative description of entropy refers to changes in the status quo of the system and is a measure of "molecular disorder" and the amount of wasted energy in a dynamical energy transformation from one state or form to another.
} 
non-useful component of energy (anergy) increases and can be in the forms of heat, gas and wastes to emit. Based on energy conservation law, the energy flows in and out of components should be equal. Due to the entropy effect, exergy flows to and from components do not balance because there is a conversion loss, or "consumption" of exergy. This may be explained as components in the system consuming exergy by virtue of the ineffectiveness of their ability to transfer available energy (Moor 1981).

Over the past 20 years, there is increasing application and recognition in industry, government and academia in many countries of the usefulness of exergy methods. Applications of exergy analysis can be found not only in the thermodynamics field, they have also been applied to fields outside, particularly, various industrial systems and environmental impact assessment (Dincer et al. 2011).

Conventional energy analysis based on the first law of thermodynamics is essentially an accounting of the energies entering and exiting. When measuring a system's energy efficiency, it is measured by the ratio of a system's energy input to its output, but it cannot tell the causes, locations and magnitudes of process inefficiencies. Thus, often the main inefficiencies are identified in the wrong sections of the system, and a different state of technological efficiency than actually exists (Dincer et al. 2011). Exergy analysis, on the other hand, highlights that although energy cannot be created or destroyed, it can be degraded in quality, eventually reaching a state in which it is in complete equilibrium with the surroundings and is therefore of no further use for performing tasks. The exergy efficiency is the ratio of the amount of thermodynamic work performed by a process (the numerator) relative to the maximum amount of work performed in theory (exergy). It is regarded as a measure of potential to cause change, and may provide the basis for an effective indicator of the potential of energy to impact the environment.

While the exergy concept has been used mostly within heat and power technology, its field of application is now being extended to the analysis of energy production and consumption. As exergy per unit quantity is in fact the physical value of a resource relative to the environment, embodied exergy analysis can provide a more direct access to evaluate the emission intensity and technology efficiency.

Drawn on thermoeconomic and system ecological studies (Sciubba 2001; Rosen et al. 2003; Odum 1996), fuel energy can be regarded as being both a public and private commodity. Just as a systems ecological analysis reveals, the emission of energy use can be treated as a commodity of negative value (Chen 2005; 2011). As the market value and material quantity of energy do not reflect the hidden cost of negative utility caused by emissions, we must resort to exergy analysis for a better understanding of how to reduce emissions.

The basics of exergy analysis

Exergy analysis is a thermodynamic analysis technique of exergoeconomics, the branch of applied thermodynamics and optimisation methods (Sciubba 2004). It is suggested that exergy is the only rational basis for assigning monetary costs to the work actually 
performed by input energy. Based on the second law of thermodynamics, ${ }^{3}$ the exergy of an energy form or substance is a measure of its usefulness, quality or potential to impact the environment. It is the maximum theoretical useful work (shaft work or electrical work) obtainable as a thermodynamic system is in a complete state of thermodynamic equilibrium under conditions of certain temperature and pressure (Tsatsaronis 2007). Some studies have proved that the deviation between energy-based and exergy-based analysis can be very large (Rosen et al. 2001; Dincer 2002). It is found that the efficiency of a steam generator on an energy base can be $95 \%$ if it is calculated by its input quantity, but only $50 \%$ efficient on exergy base. Most of the exergy losses in the steam generators are associated with internal consumption. This discrepancy implies that although most of the input energy is transferred to the preheated water, the energy is degraded in the process.

In recent years, many studies of the environmental impact of manufacturing processes have adopted exergy analysis methods. By comparing energy and exergy losses in the manufacturing process and pricing differences between the two (Wall 1977), it has proved that exergy-based analysis can be a simple method and may develop conventions and standards for technical improvements for long-term planning. Based on the definitions of Renaldi et al. (2011), Wall (1977), Tsatsaronis (2007) and especially Szargut's (2002) breakthrough contribution to the calculation of exergy, we are able to rationalise the proposed exergy approach.

Firstly, exergy is a general measure of the quality of natural resources. In a fuel combustion system, there are four different types of exergy $E$, denoted respectively as kinetic, potential, physical and chemical exergy. Kinetic and potential exergy have the same meaning as the corresponding energy terms and can be disregarded for the purposes of analysing most common industrial processes. Physical exergy is "the work obtainable by taking a substance through reversible physical processes from its initial state (temperature $T$, pressure $p$ ) to the state determined by the temperature $T_{\mathrm{o}}$ and the pressure $p_{\mathrm{o}}$ of the environment" (Szargut et al. 1988). Physical exergy assumes an important role for the purposes of optimisation of thermal and mechanical processes, including heat engines and power plants. But it is of secondary importance, or even negligible when attention is focussed on emissions from fuel combustion in the manufacturing processes. In this case, chemical exergy plays a major role in calculating embodied energy and in environmental analysis. Chemical exergy is "the work that can be obtained by a substance having the parameters (temperature $T$ and the pressure $p$ to a state of thermodynamic equilibrium with the datum level components of the environment" (Szargut et al. 1988).

Secondly, energy is motion or ability to produce motion while exergy is work or ability to produce work (Wall 1977). The exergy flow in a process can be expressed as products, wastes, emissions and heat losses, respectively. The last one, heat losses, is the production of entropy in the process. Thus, not all exergy output can be considered as useful output. Material wastes, emissions and heat losses are external

\footnotetext{
${ }^{3}$ The law of thermodynamic entropy production is alternatively expressed in terms of exergy consumption, that is, exergy can never be created: it is always consumed in a real irreversible process, with the only exception being an idealised reversible or equilibrium process (Chen 2005)
} 
exergy losses. To split embodied exergy in products $E_{P}^{x}$ in the energy resource $E_{R}^{x}$ from the loss exergy (anergy) $E_{L}^{x}$, the equation can be rewritten as:

$$
E_{P}^{x}=E_{R}^{x}-E_{L}^{X}
$$

Thirdly, the exergy losses are the results of entropy generation partially caused by the fuel components, and partially caused by technological inefficiency. By distinguishing the inefficient causes from the deadweight losses of exergy, we can use exergy loss as a measure to calculate the ecological cost thus incurred, a negative value-added, so to speak, and to determine what are the necessary incentive financial instruments for green production and GHG mitigation.

Most of the literature on exergy-based analysis is concentrated in the areas of thermo-engineering, environmental and ecology. It produces well-grounded formulations to calculate both positive exergy and negative exergy. However, it is found to be difficult and complicated when applied directly in economic analysis. With limited journal articles on the economic aspects, Sciubba (2001) focuses on macro space and time integral of primary energy, and Bo Zhang et al. (2012) uses exergy-based analysis for an empirical study of the emissions from China's industrial sectors with clustering and disjoint principle component analysis to calculate the exergy contents of the emissions. The methods they use are all based on thermodynamic tools, though very applicable, yet with stringent constraints, including temperature and operation environment parameters. To solve this difficulty, Szargut and Stanek $(2002 ; 2008)$ introduce the index of ecological cost, defined as the cumulative consumption of nonrenewable exergy in fabricating a particular product plus the compensation of environmental losses caused by rejection of harmful substances to the environment. Based on a thermo-ecological cost balance equation, the dimensionless index expresses the ratio of thermo-ecological cost of the $i$ th product related its specific exergy. The lower the index value, the better from the ecological point of view, believing that we pay less cumulative exergy of natural resources per unit of particular products.

In theory, exergy analysis complements the widely used "energy intensity" which can only measure quantity, but not the quality. Exergy analysis enables us to determine the locations, types and true magnitudes of wastes and losses. This actually lays a scientific basis for internalising the cost of environmental recovery incurred by production emissions. Just as Zhang et al. (2012) noted, the measure of pollution was modified into embodied exergy or exergy emitted as "ecological cost" to make up for the polluted environment. As a special corollary, the maximum exergy production efficiency principle for a production value chain can then be converted to the principle of maximum profit for sustainable economic development.

\section{Accounting embodied exergy flow}

Setting the boundary for embodied exergy analysis

There are two ways to define embodied energy consumption flow. Firstly, it may refer to the total input of fuel energy including the fossil fuel and non-fossil fuel in 
products' production process. Secondly, it may also refer to the aggregate input of all kinds of invested energy including fuels, materials and manpower. This study adopts the first definition, with its complete definition quoted from UNIDO's Industrial Development Report (2011): "Embodied energy refers to the cumulative amount of commercial energy (fossil, renewable and nuclear) invested to extract, process and manufacture a product and transport it to its point of use. This accounting concept sums the energy physically embodied in the materials (which can be released by reversing the process) and the energy invested in creating the processing conditions and bringing the materials together (including transport)."

It can be further inferred from this that embodied exergy consumption flow refers to the cumulative amount of useful energy invested in a production process minus its losses including heat, material waste and emissions.

Basically, there are two types of research design: product-specific and processbased analysis methods, each of different analytical utility. For the product-specific analysis, which is now being applied in civil engineering and thermo-engineering industries, its measurement is based on the thermodynamic analysis of chemical compositions of specific products, and sets its boundary starting with an input material as a final product (e.g. cement for building) and traces backward to the direct energy inputs or sequestered energy of each contributing material (i.e. water, limestone, etc.) (Dixit et al. 2010). This method is also applied in principle components analysis for environmental emissions (Zhang et al. 2012).

The second approach is process-based analysis or supply chain analysis (Nishimura et al. 1996; Seow and Rahimifard 2011; Bordigoni et al. 2012; Kara et al. 2010; 2011). Based on the energy conservation law and life cycle theory, it provides three major analytical boundary setting techniques: (a) "Cradle-to-gate analysis" which includes all energy (in primary form) until the product leaves the factory gate, (b) "cradle-to-grave analysis" which starts from the extraction of raw materials (including fuels) until the end of the products' life cycle (including energy from manufacturing, transport, energy to manufacture capital equipment, heating and lighting of factory, maintenance, disposal etc. and (c) "cradle-to-site analysis" which includes all of the energy consumed until the product has reached the point of use (production cost + freight).

Integrating embodied exergy into decomposition methods

Available decomposition methods are successful in analysing the sectoral energy consumption, yet they still cannot fully reflect the factors that determine energy usage from the technological aspects to distinguish the positive work from negative work of energy usage. The discussion in this section is intended to fill this gap by integrating the embodied exergy analysis method with decomposition techniques into a pragmatic analytical tool.

1. Identifying different decomposition methods

Much has been written about decomposition techniques (Ang 1995; Sun 1998). The general function of decomposition techniques is to study the impacts of structural differences and changes in sectoral energy efficiency improvements. Three major approaches can be identified: the energy intensity approach, energy 
consumption approach and energy coefficient approach.

The energy intensity approach studies about the effects of changes in sectoral production mix or activities, or changes in subsectoral energy intensities on the total sectoral energy intensity. Based on Greening et al. (1997), the energy intensity approach has the advantage of easy presentation of the results because the estimated effects are normally expressed in indices. The two index decomposition methods most commonly used are the Laspeyres or the simple average Divisia. The Laspeyres compares each of the components of energy usage patterns with a fixed base year, while holding the other components constant. As a result, this index does not have the time or factor reversal properties of an ideal price index (Fisher 1972). As opposed to the Laspeyres index, the Divisia index, as with the Cobb-Douglas index, does have the time reversal property but does not have the factor reversal property.

The energy consumption approach involves decomposition of the change in industrial energy demand between 2 years or in the ratio of the energy consumption of 1 year to that of another. It studies the effects associated with the changes in aggregate production level, structural change in production and changes in sectoral energy. A comparative study done by Greening et al. (1997) shows that the results of using either fixed-year or time-series Laspeyres techniques tend to underestimate the effects for both energy intensity and activity mix on aggregate energy intensity. Meanwhile, using the simple average Divisia fixed base year technique tends to overestimate the effects of both energy intensity and activity mix on aggregate energy intensity.

The energy coefficient approach is based on the energy consumption approach and was developed by Ang and Lee (1996) to study the impacts of structural change and changes in energy efficiencies in industrial sectors. Its major contribution is to break down the aggregate energy coefficient or elasticity for industrial energy demand into contributions from different factors including industrial energy consumption, industrial production and energy intensity at both the total and sectoral levels. By estimating the ratio of the fractional change in primary energy consumption in a specific industrial sector to the fractional change in total industrial national output, its inventors propose to identify the past evolving patterns of industrial energy consumption and the relative contributions of different factors to changes in energy demand. More importantly, Ang and Lee set three parameters to reflect the production effect $\left(e_{\mathrm{pdn}}\right)$, structural effect $\left(e_{\mathrm{str}}\right)$ and intensity effect $\left(e_{\text {int }}\right)$, respectively, for the energy consumption in a production process in a given period. They also for the first time brought into the decomposition analysis the concept of a residual term, $e_{\mathrm{rsd}}$, as they noticed there existed an efficiency difference between the changes in total industrial energy consumption efficiency $\left(e_{\mathrm{ct}}\right)$ and the total sum of the estimates of the three effects.

The factorisation technique applied is calculated on the basis of the ratio changes of energy production $\Delta E$ to value production $\Delta P$ and between a time period 0 to $t$. Their general mathematic expression is as follows:

$$
\left(e_{x}\right)_{0, t}=\left[\left(\Delta E_{x}\right)_{\mathrm{o}, t} / E_{\mathrm{o}}\right] / \Delta P_{o, t} / P_{\mathrm{o}}
$$


where $e_{x}$ represents the three different variables mentioned above. By using the parametric estimation method, the three sub-coefficients are each assigned with a quotient calculated with the Laspeyres-based parametric Divisia method. The coefficient approach draws attention to the different factors that might affect energy consumption in the production process. It sets up an analytical causal linkage between energy consumption and production process.

In sum, the different decomposition approaches proposed and applied share the same study objective and have proved to be useful in identifying the changes of industrial energy demand. But as has been discussed above, the merits of the three methods are confined to aggregate energy consumption analysis and projection.

2. The exergy-based decomposition method

The major function of the exergy-based decomposition method is to differentiate the positive energy from the negative energy in a production unit. It is also able to determine the work efficiency of exergy and estimate emission impacts caused by engineering management inefficiencies. The exergy-based decomposition method is built on the concept of exergy and anergy as two components in energy, and exergy efficiency is a measure of GHG emissions. It serves to break down the aggregate energy coefficient or elasticity for industrial energy demand into contributions from exergy and anergy factors. The proposed exergy-based decomposition procedures include defining time and scale scalars, parameters, factorised quotients, data synthesis and analysis:

i. Time scalar. A period wise (PW)- or a time series (TS)-based data analysis are two commonly used methods for time measurement. The one chosen depends on data availability, depth of analysis and, to some extent, the decomposition approach used. As period wise analysis is more likely to be used in multi-country analysis because less data is needed, and time series analysis is more likely to be used together with the energy intensity approach because presentation and interpretation of the results are easier. For the purpose of this study, a 1-year data analysis was adopted.

ii. Data scale. Exergy-based analysis targets at specific sector and products and there are three different sector classification practices: (a) to follow an international standard classification, (b) to group together industrial activities related in terms of energy use patterns and (c) to single out a few major energy-intensive sectors. We chose to use sector disaggregation data for manufactured products for a selection of industrial sectors to compare the embodied energy in intermediate products. This provided the advantage of linking energy consumption with pre-defined manufacturing processes and products.

iii. Parameters. This study is confined to sectoral industrial products with the variables defined as follows:

$Q_{t} \quad$ Total industrial energy input

$Q_{i} \quad$ Energy input in industrial sector $i$

$P_{t} \quad$ Total industrial output

$P_{i} \quad$ Production output of sector $i$ 
$V_{i m}$ The import value of products in sector $i$

$V_{e x}$ The export value of products in sector $i$

$E_{i}^{x} \quad$ The exergy of energy input in sector $i$

$E_{p, i}^{x} \quad$ Product exergy in sector $i$

$E_{a, i}^{x} \quad$ Anergy in sector $i$, the sum of $E_{R}^{x}, E_{M}^{x}, E_{P}^{x}, E_{H}^{x}, \Delta E^{\mathrm{x}}$

$E_{e}^{x} \quad$ Exergy production efficiency $\left(=E_{p}^{x} / Q_{i}\right)$

$E_{v, i m}^{x}$ Embodied exergy in per unit value import products

$E_{v, \text { ex }}^{x}$ Embodied exergy in per unit value export products

iv. Exergy value accounting. The embodied exergy in products is decided by the system environment. In the case of fuels, namely coal, fuel oil and natural gas, the exergy content was estimated by multiplying the net heating value by an appropriate coefficient. As more detailed treatment of the exergy formula is beyond the scope of this work, we adopted, for convenience, Szargut's (2002) chemical exergy coefficient and Ayres' table (Ayres 2006) for embodied exergy accounting as follows:

v. For the decomposition formulation, we adopted the additive form and set a 1 -year period for the "from-cradle-to-gate" production process. The decomposition procedures for computing the chemical exergy content in products included the following steps:

a. Compute the total exergy of energy input in a predefined industrial sector:

$$
E_{i, j}^{x}=\sum_{i=1}^{n} \sum_{j=1}^{m} Q_{i, j} \cdot \lambda_{i, j}
$$

where $Q_{i, j}$ denotes the $i$ th fuel input in $j$ th sector. It had to be converted into thermo units by net heat value. For $\lambda$, we adopt Ayres' coefficients in Table 1.

b. Based on Eq. 1, the $E_{i, j}{ }^{x}$ consists of the product exergy $E_{p, i}{ }^{x}$ and the loss exergy $E_{a, i}{ }^{x}$, the embodied exergy in products should be expressed as:

$$
E_{p, i}^{x}=E_{i, j}^{x}-E_{a, j}^{x}=\left(\sum_{i=1}^{n} \sum_{j=1}^{n} Q_{i, j} \cdot \lambda_{i, j}\right)-E_{a, i}^{x}
$$

Table 1 Chemical exergy content of some fuels

Source: Ayres 2006

\begin{tabular}{llll}
\hline Fuel & $\begin{array}{l}\text { Exergy } \\
\text { coefficient }\end{array}$ & $\begin{array}{l}\text { Net heat value } \\
(\mathrm{kJ} / \mathrm{kg})\end{array}$ & $\begin{array}{l}\text { Chemical exergy } \\
(\mathrm{kJ} / \mathrm{kg})\end{array}$ \\
\hline Coal & 1.088 & 21,680 & $23,587.84$ \\
Coke & 1.06 & 28,300 & 29,998 \\
Fuel oil & 1.073 & 39,500 & $42,383.5$ \\
Natural gas & 1.04 & 44,000 & 45,760 \\
Diesel fuel & 1.07 & 39,500 & 42,265 \\
\hline
\end{tabular}


As $E_{a, i}{ }^{x}$ is subject to the energy property and production environment, we therefore kept it as a variable, and because of these losses, only a certain percentage per unit of exergy supplied to a system can be usefully exploited. As it is the exergy losses that release into the environment and produce harmful effects, we adopted the IPCC's $\mathrm{CO}_{2}$ emission factors to calculate the losses cost.

c. Compute the content of embodied exergy in per unit production output value:

$$
E_{p, j}^{x} \text { per unit }=\frac{E_{i, j}^{x}-E_{a, i}^{x}}{P_{i, j}}
$$

There are three options for calculating $E_{a, i}{ }^{x}$ : in natural units using the quantities of substances, as IPCC has provided, or in monetary units resulting from the estimation of economic losses caused by harmful substances emitted into the environment, or in exergy units resulting from depletion of nonrenewable resources required to prevent. For the purpose of this study, we adopt the exergy method using emission factors $\varepsilon=4.4 \mathrm{MJ} / \mathrm{kg}$ in exergy provided by Stanek et al. (2011), expressed as.

$$
E_{a, i}^{x}=E_{i, j}^{x} \bullet \varepsilon
$$

d. Compute the content of embodied useful exergy in per unit import/export products:

$$
E_{p, i m / e x}^{x} \text { perunit }=V_{\text {im }} \cdot E_{p, j}^{x} \text { perunit }
$$

\section{An accounting of the embodied exergy flow in traded manufactured products between the EU and China and Japan}

Data and synthesising procedures

One of the big challenges in this study was synthesising data from different sources. In order to best present the embodied exergy in intermediate products ${ }^{4}$, we chose 2009 data from the United Nation's Broad Economic Categories (BEC) as the classification standard for this analysis.

China and Japan are the EU's two top trading partners from the East Asian region, accounting for $72.5 \%$ of imports from and $56.97 \%$ of exports to the EU. Over $80 \%$

\footnotetext{
${ }^{4}$ Intermediate goods can be parts and components or any other item used as an input in the production of manufactured goods for final consumers. Goods classified as "intermediate inputs" are by "product type" and not by "use" as in input-output tables. The former is used to approximate the latter since the latter is not available at the six-digit HS commodity level
} 
Table 2 The decomposition of embodied exergy in industrial sectors

\begin{tabular}{llllllll}
\hline Country & $\begin{array}{l}\text { Exergy } \\
\text { (GJ) }\end{array}$ & $\begin{array}{l}\text { Anergy } \\
\text { (GJ) }\end{array}$ & $\begin{array}{l}\text { Anergy } \\
\%\end{array}$ & $\begin{array}{l}\text { U exergy* } \\
\text { (GJ) }\end{array}$ & $\begin{array}{l}\text { Output } \\
\text { (billion\$) }\end{array}$ & $\begin{array}{l}\text { Unit exergy } \\
\text { (GJ/billion\$) }\end{array}$ & $\begin{array}{l}\text { Unit U exergy } \\
\text { (GJ/billion\$) }\end{array}$ \\
\hline EU & $5,660.87$ & 5.72 & 0.001 & $5,655.15$ & $6,626.65$ & 0.85 & 0.85 \\
China & $19,966.2$ & 7.95 & 0.03 & $19,954.48$ & $7,146.90$ & 2.79 & 2.79 \\
Japan & $2,397.97$ & 0.79 & 0.0003 & $2,397.18$ & $2,814.71$ & 0.85 & 0.85 \\
\hline
\end{tabular}

Source: Energy data from IEA; output data from UNIDO 2012

$U$ exergy useful exergy

of the total EU exports are manufactured products, and of the exports to China and Japan, $52 \%$ more are intermediate products. Thus, Japan and China were used as two contrasting examples for the analysis of embodied exergy flow between the EU and East Asian region.

The industrial sector output data came from UNIDO's Industrial Statistics Database (INDSTAT4 2012), and the energy data were mainly from the IEA (2011)'s sectoral energy consumption data. To match BEC's classification, we adjusted certain items against the data issued by China's Statistical Bureau and Japan's Ministry of Economy, Trade and Industry.

Firstly, for the convenience of comparison, we first converted all the energy carriers into unified oil equivalent units and used exergy coefficients and lower heating values for fuel oil to calculate the total chemical exergy of combustible energy. The result of this calculation indicated the total quantity of available or useful exergy in an energy carrier, and more importantly, depicted the portion of the waste exergy and its impact on the industrial and trade policy-making. Secondly, we calculated the waste exergy of different energy carriers with reference of Stanek et al.'s (2011) energy loss ratio and properties of carbonbased fuels (Table 2). And thirdly, the trade volume between the EU and China/Japan (Table 3) was compiled according to the BEC classification with the UN comtrade data shown in Table 4.

Embodied exergy flow in manufactured products trade

The study showed that when all the available exergy is put to use in production, the aggregated useful embodied exergy in the industrial sectors of the EU, China and Japan totalled about 975.18 GJ per billion dollars of trade value. The total exergy

Table 3 A balance account of embodied exergy flow in manufactured products

Unit: GJ/billion\$

\begin{tabular}{llll}
\hline Exergy flow & EU & China & Japan \\
\hline Import & 899.53 & 95.71 & 41.54 \\
Export & 137.25 & 833.89 & 65.64 \\
Balance & +762.28 & -738.18 & -24.1 \\
\hline
\end{tabular}




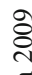

司

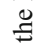

范

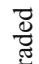

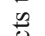

응

ت

.

ह

.

항

ल

릉

敢

:

है

$\stackrel{\Xi}{\Xi}$

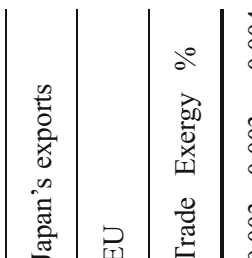

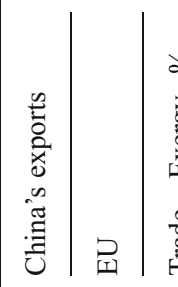

.

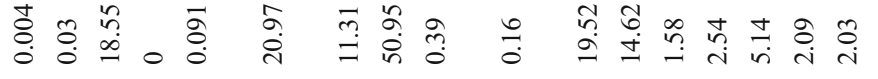

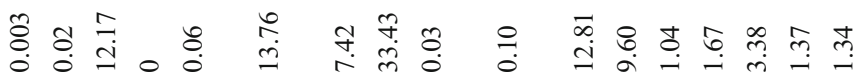

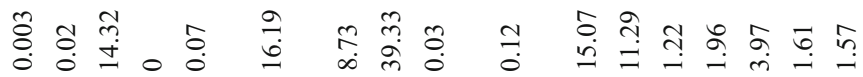

둥 \&

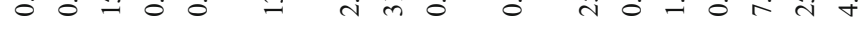

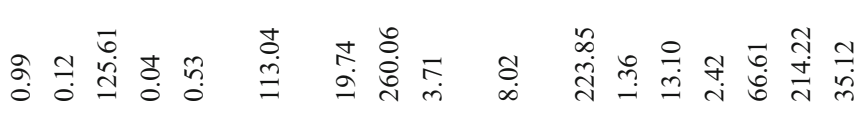

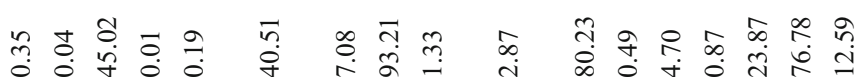

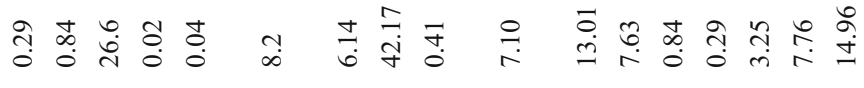

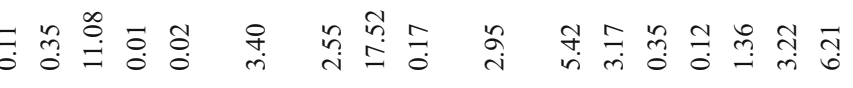

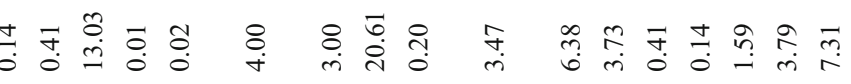

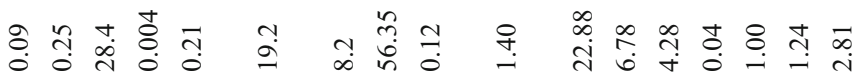

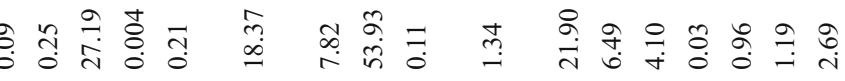

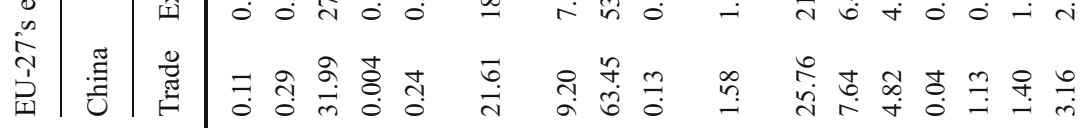

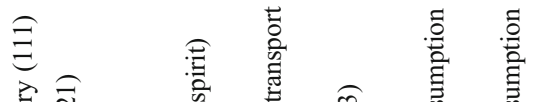

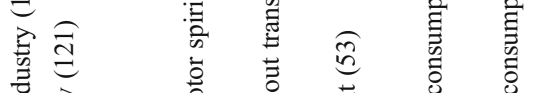

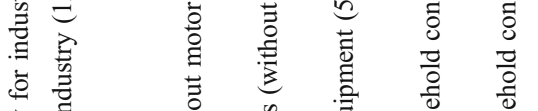

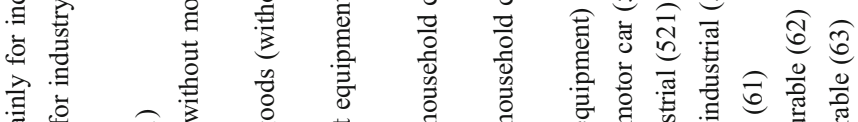

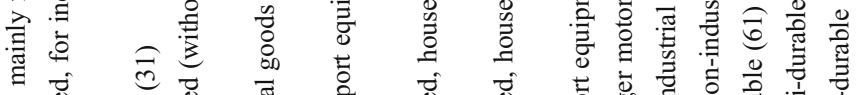

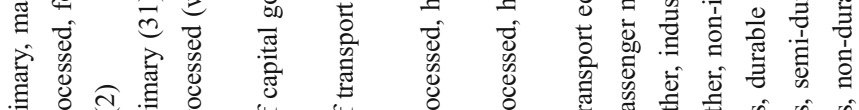

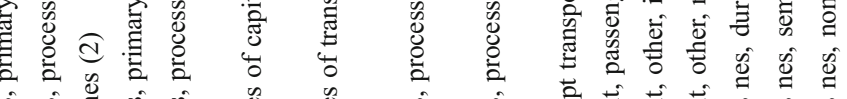

की की

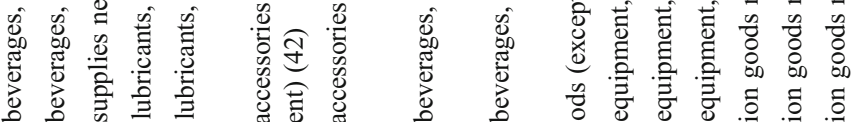

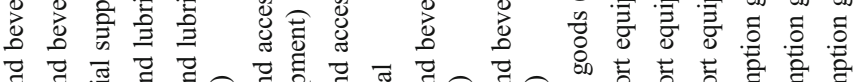

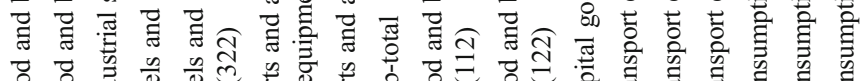

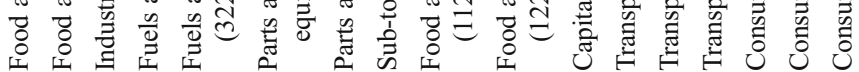




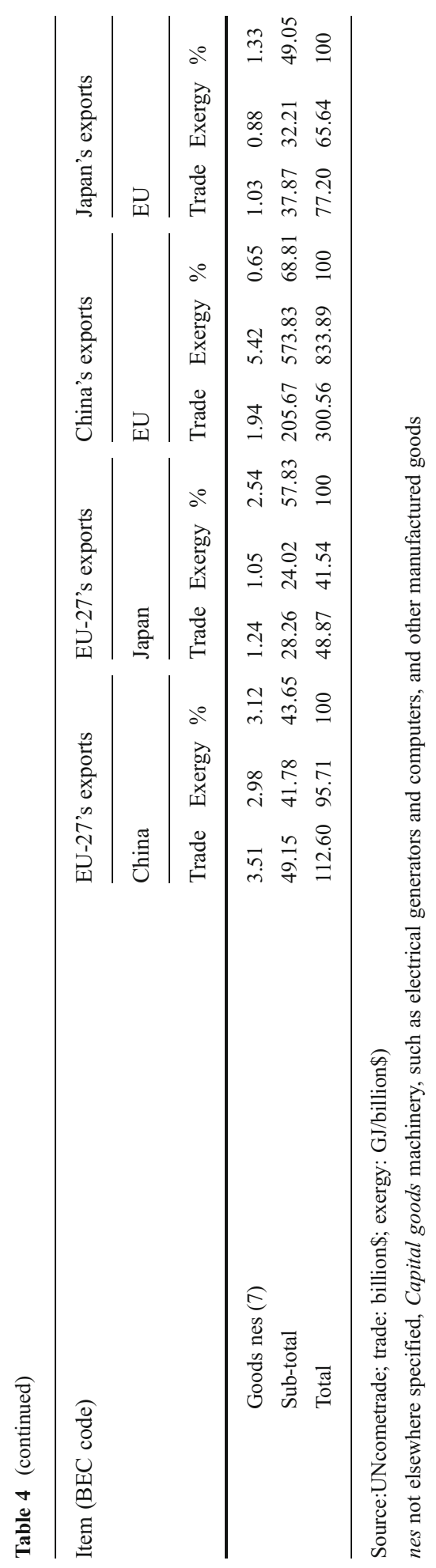




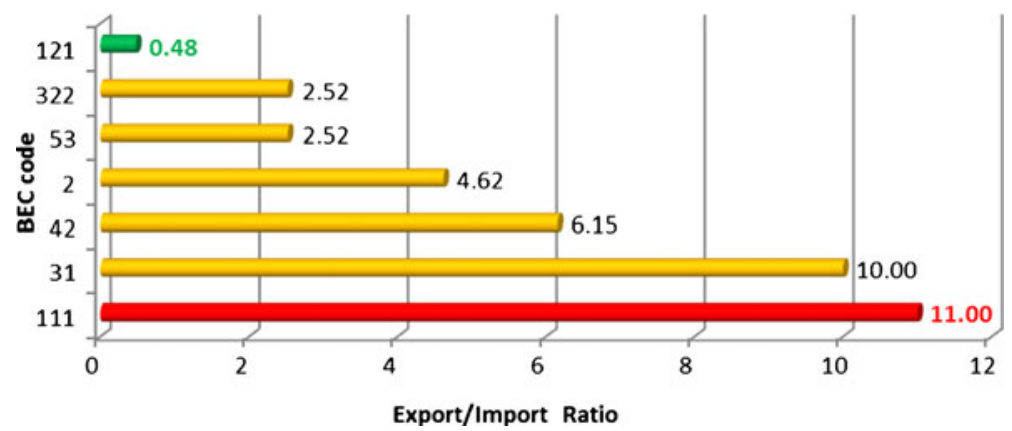

Fig. 1 China's intermediate products export-import ratio with the EU

losses were approximately $15.25 \mathrm{GJ}$ per billion dollars. When we set up a balance account of embodied exergy flow in manufactured products between the three trade partners, we found that the EU enjoyed a surplus of embodied exergy consumption, while China and Japan both suffered from a deficit of embodied exergy export, and these two countries actually burden the negative environmental and social effects resulting from exergy losses.

However, according to the studies carried out by Saxena from the Asian Productivity Organisation (2009) and the European Commission (2009), there exist universally 20 to $30 \%$ more onsite exergy losses in manufacturing processes as a result of technological barriers. Since there is no available data for specific sectors, we can simply assume that the estimated exergy losses (anergy) in Table 2 are the sunk losses determined by the properties of different fuels, while there is an extra loss resulting from low technological and management efficiencies. That is, we need to deduct 20 to $30 \%$ more exergy from the nominal embodied useful exergy in products.

Another important discovery, as Fig. 1 shows, is that by comparing the two major intermediate products trade data, both China and Japan had surpluses for the intermediate food and beverage products under BEC items 111 and 121 (Fig. 2).

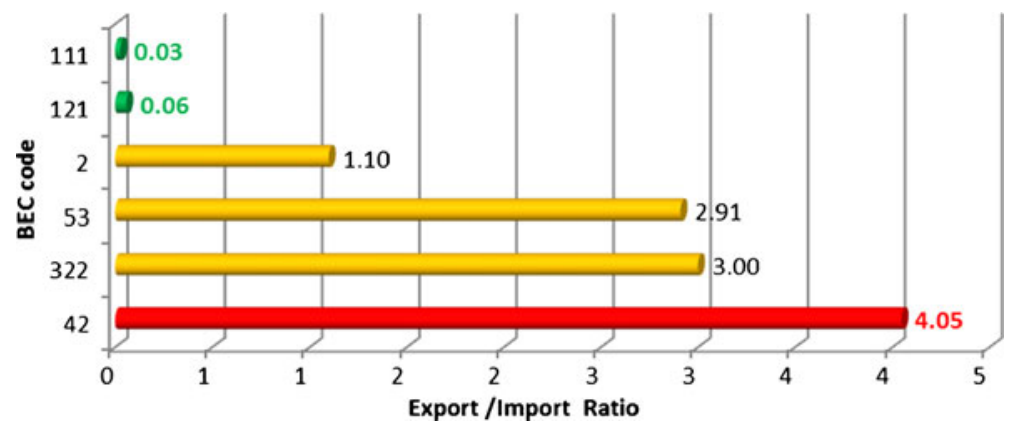

Fig. 2 Japan's intermediate products export-import ratio with the EU 


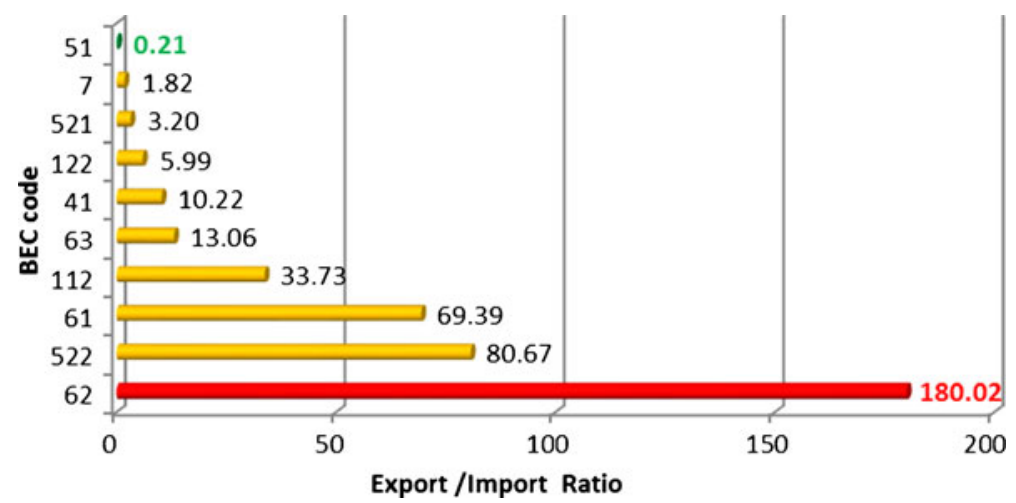

Fig. 3 China's embodied exergy in final manufactured products trade with the EU

For the embodied exergy in final products, China had a surplus for transport equipment under BEC 51 with the EU (Fig. 3), and Japan had surpluses for five items with the EU (Fig. 4).

\section{The policy implications of embodied exergy flow analysis}

The embodied exergy analysis has provided some new foci to reconsider with respect to international governance theory for energy-saving and GHG emission mitigation drives.

The new trade pattern and embodied exergy flow

The world trade pattern is now undergoing a structural change driven by global economic integration. The manufacturing industries: typically electronic, automobiles, apparel and footwear have their production increasingly segmented across regions. The intermediate goods trade or foreign value-added products have been growing. In 2009, trade in intermediate goods accounted for $50 \%$ more of non-fuel world merchandise trade. Analysis of embodied exergy flows in industrial products

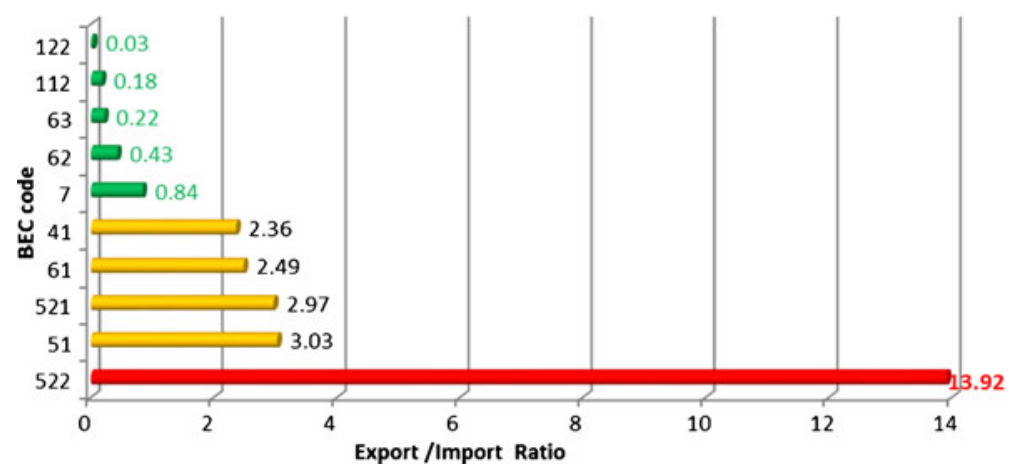

Fig. 4 Japan's embodided exergy in final manufactured products trade with the EU 
between the EU and China/Japan demonstrates that energy issues can no longer be treated separately from the product carrier, as the global production value chain has segregated both its economic and environmental benefits and costs from producers and consumers.

According to the statistics, the production and export of intermediate inputs have been mainly concentrated in Europe and Asia, each accounting for 41 and $35 \%$ in total world exports of intermediate goods, while the interregional import flows of intermediate goods between Europe and Asia topped US\$384 billion (IDE-JETRO and World Trade Organization 2011). In Europe, about two-thirds of the European imports are intermediate goods and raw materials, especially a large part of which are processed for re-export (De Gucht 2012). This study has demonstrated that the EU has enjoyed an overall surplus of intermediate products trade with both China and Japan, although the overall trade balance of goods was negative in 2009. One of the positive impacts is on the total factor productivity of industries (Miroudot et al. 2009). This is not only the attraction of the more productive foreign technologies embodied, more importantly it is that by the establishment of cross-region production value chains, a country may choose to import comparatively environmental friendly intermediate goods or final products, leaving the comparatively polluting ones to other countries. The result is that some countries, especially underdeveloped countries, will suffer the depletion of non-renewable resources. Environmental degradation is usually accompanied by public health costs.

If we look at this issue not merely in terms of short-term economic returns, but also from the viewpoint of long-term sustainable development, we should redefine the "joint but different responsibility" as "joint production and shared responsibility."

Embodied useful exergy flow, ecological cost and carbon evasion

It is not too rash to say that most of the debates on energy-related pollution taxation in economics overlook the chain effects of energy consumption embodied in products. We can conclude that the exergy losses and negative environmental impacts induced by heat generation in the process of work can be adequately measured with thermodynamic tools and the costs can be monetised. As discussed above, if all the useful exergy is fully utilised, only a very small portion of waste exergy will be emitted into the environment and it will not harm the environment. The harm comes mainly from the under-utilised useful exergy, since 20 to $30 \%$ more of the exergy losses are the result of low operation efficiencies. If we can precisely determine the losses caused by inefficient management, and monetise the costs thereby incurred, rather than put claims on total energy consumption, it is possible to develop policy instruments to mitigate the emissions. This is perhaps why there seems to be no real progress towards an effective carbon tax mechanism.

What we propose by measuring the ecological costs based on exergy efficiency and by designing a tax mechanism on "negative VAT" to compensate producers for investing in green technology will direct public attention away from "the quantity of energy used" to "quality of energy used." This will cultivate a new social consensus about carbon civilisation and deter carbon evasion behaviour. 


\section{Conclusion}

The efficient use of energy resources cannot be effectively implemented unless we treat energy as both a public and private good with joint production and shared responsibility. It will not help if we still cling to the transaction value of energy without distinguishing the positive value from the negative value of energy use. Joint production and taking care of our shared environment require us to step out of the confines of national boundaries and to enrich our knowledge about energy resources.

This is only a preliminary study on the concept of embodied exergy and its decomposition method. It might be more interesting if we could differentiate the three trading partners by using specified parameters for each. For example, we could go deeper and compare the energy mix in each partner's industrial sector, the productivity as well as its value-added capacity in order to get a more thorough understanding about its causes and effects.

The issues raised here require further study, namely, the specific ecological costing methods when estimating both the value of exergy loss and a tax base. Secondly, the value-added feature in the embodied exergy flow should be an important aspect if we want to use it as a metric to determine the location of production. Exergy analysis is found to provide the most correct and insightful assessment of thermodynamic features of any process and to offer a clear quantitative indication of both the irreversibilities and the degree of matching between the used resources and the end-use materials or energy flows. However, if it is applied in economic analysis more work on it is required.

Acknowledgements This study was funded by the Humanities and Social Sciences Project of China's Ministry of Education (no. 09YJA790011) and the China National Social Science Fund (project no. 12BJY060)

Open Access This article is distributed under the terms of the Creative Commons Attribution License which permits any use, distribution, and reproduction in any medium, provided the original author(s) and the source are credited.

\section{References}

Ang BW (1995) Decomposition methodology in industrial energy demand analysis. Energy 20(11):10811095

Ang BW, Lee PW (1996) Decomposition of industrial energy consumption: the energy coefficient approach. Energy Econ 18:129-143

Ayres RU (2006) An application of exergy accounting to five basic metal industries. In: A. von Gleich et al. (eds), Sustainable Metals Management, pp 141-194.

Bordigoni M et al (2012) Role of embodied energy in the European manufacturing industry: application to short-term impacts of a carbon tax. Energy Policy 43:335-350

Chen GQ (2005) Exergy consumption of the earth. Ecol Model 184:363-380

Chen ZM, Chen GQ (2011) An overview of energy consumption of the globalized world economy. Energy Policy 39:5920-5928

Costanza R (1980) Embodied energy and economic valuation. Science, New Series 210(4475):1219-1224

De Gucht K (2012) 2012 EU-ASEAN Business Summit. http://europa.eu/rapid/press-release_SPEECH-12253 en.htm. Assessed 26 Aug 2012

Dincer I (2002) The role of exergy in energy policy making. Energy Policy 30:137-149 
Dincer I et al. (2011) Exergy analysis of green energy systems. In Xianguo Li (ed) Green energy: basic concepts and fundamentals. Springer, New York

Dixit MK et al (2010) Identification of parameters for embodied energy measurement: a literature review. Energy and Buildings 42:1238-1247

European Commission (2009) ICT and energy efficiency - the case for manufacturing. http:// www.europa.eu. Assessed 26 August 2012

Fisher I (1972) The making of index numbers. Houghton Mifflin, Boston

Georgescu-Roegen N (1971) The entropy law and economic process. Harvard University Press, Cambridge

Greening LA et al (1997) Comparison of six decomposition methods: application to aggregate energy intensity for manufacturing in 10 OECD countries. Energy Economics 19:375-390

IEA (2011) Key World Energy Statistics 2011. http://www.iea.org. Assessed 26 August 2012

IDE-JETRO and World Trade Organization (2011) Trade patterns and global value chains in East Asia: from trade in goods to trade in tasks. http://www.wto.org. Assessed 26 August 2012

Jørgensen SE et al (2004) Emergy and exergy stored in genetic information. Ecol Model 178:11-16

Kara S et al (2010) Global manufacturing and the embodied energy of products. CIRP Ann Manuf Technol 59:29-32

Kara S et al (2011) Embodied energy of manufacturing supply chains. CIRP J Manuf Sci Technol 4:317-323

Miroudot S et al. (2009) Trade in Intermediate Goods and Services, OECD Trade Policy Working Article No. 93. http://www.oecd.org. Assessed 26 August 2012

Moor DF (1981) Thermodynamic principles of energy degrading. Macmillan, London

Moran DD et al (2009) Trading spaces: calculating embodied ecological footprints in international trade using a product land use matrix (PLUM). Ecol Econ 68:1938-1951

Nishimura K et al (1996) Derivation of energy-embodiment functions to estimate the embodied energy from the material Content. Energy 21(12):1247-1256

Odum HT (1996) Environmental accounting: emergy and environmental decision making. Wiley, New York

Renaldi K et al. (2011) Exergy efficiency definitions for manufacturing processes. In: J Hesselbach and C Herrmann (eds), Glocalized Solutions for Sustainability in Manufacturing: Proceedings of the 18th CIRP International 329, Conference on Life Cycle Engineering, Technische Universität Braunschweig, Braunschweig, Germany, May 2nd-4th, doi:10.1007/978-3-642-19692-8 57: (C) Springer, Berlin

Rosen MA et al (2001) Exergy as the confluence of energy, environment and sustainable development. Exergy Int J 1(1):3-13

Rosen MA et al (2003) Exergy-cost-energy-mass analysis of thermal systems and processes. Energy Conversion and Management 44:1633-1651

Saxena AK (2009) Greenhouse gas emissions: estimation and reduction. Asian Productivity Organization. http://www.apo-tokyo.org. Assessed 25 June 2012

Szargut J et al (1988) Exergy analysis of thermal, chemical and metallurgical processes. Hemisphere, New York

Szargut J (2002) Application of exergy for the determination of the proecological tax replacing the actual personal taxes. Energy 27:379-389

Szargut J, Stanek W (2008) Influence of the pro-ecological tax on the market prices of fuels and electricity. Energy 33:137-143

Sciubba E (2001) Beyond thermoeconomics? The concept of extended exergy accounting and its application to the analysis and design of thermal systems. Exergy-Int J 1(2):68-84

Sciubba E (2004) Exergoeconomics. Encyclopedia of Energy 2

Seow Y, Rahimifard S (2011) A framework for modeling energy consumption within manufacturing systems. CIRP J Manuf Sci Technol 4:258-264

Stanek W et al. (2011) Influence of $\mathrm{CO}_{2}$ mitigation on economic and thermo-ecological cost. Institute of Thermal Technology. www.itc.polsl.pl. Assessed 30 July 2012

Sun JW (1998) Changes in energy consumption and energy intensity: a complete decomposition model. Energy Economics 20:85-100

Tsatsaronis G (2007) Definitions and nomenclature in exergy analysis and exergoeconomics. Energy 32:249-253

UNIDO, Industrial Development Report 2011. http://www.unido.org. Assessed 30 June 2012

Wall G (1977) Exergy - a useful concept within resource accounting. Research Report No.77-42. Institute of Theoretical Physics, Göteborg, Sweden

Zhang B et al (2012) Environmental emissions by Chinese industry: exergy-based unifying assessment. Energy Policy 45:490-501 